\title{
Lobular neoplasia found on breast biopsy: marker of increased risk of malignancy or direct pre-cancerous lesion?
}

\author{
Bartłomiej Szynglarewicz ${ }^{1}$, Rafał Matkowski1, ${ }^{1,}$, Agnieszka Hałoń ${ }^{3}$, \\ Piotr Kasprzak $^{4}$, Józef Forgacz ${ }^{1}$, Iwona Gisterek ${ }^{2}$, Jan Kornafel ${ }^{2}$
}

${ }^{1} 2^{\text {nd }}$ Department of Surgical Oncology, Lower Silesian Oncology Center

- Regional Comprehensive Cancer Center, Wroclaw, Poland

${ }^{2}$ Department of Oncology, Wroclaw Medical University, Wroclaw, Poland

${ }^{3}$ Department of Pathomorphology, Wroclaw Medical University, Wroclaw, Poland

${ }^{4}$ Breast Imaging and Minimal-invasive Biopsy Service, Lower Silesian Oncology Center

- Regional Comprehensive Cancer Center, Wroclaw, Poland

\begin{abstract}
The aim of this study was to compare the imaging symptoms and microscopic findings in females with lobular neoplasia (LN) found on biopsy. 1,478 women who underwent primary open biopsy or surgical excision after percutaneous biopsy were reviewed. In 24 of them (1.6\%), $\mathrm{LN}$ was found. In four patients, excisional biopsy with hook-wire localization was done primarily due to the radial scar. In 20 females, surgical excision of BIRADS 4 lesion was performed because of the presence of LN in specimens from the vacuum-assisted or core-needle percutaneous biopsy. Postoperative pathologic findings were compared to the radiological symptoms. In 13 women, LN did not produce any radiological symptoms and was an additional histologic finding existing near the other lesion: fibroadenoma and radial scar. In none of these lesions was an invasive cancer noticed. In one single patient, ductal carcinoma in situ was observed in the other segment of the breast. Invasive ductal cancer developed in the contralateral breast in one patient. In 11 patients, $\mathrm{LN}$ was diagnosed due to radiological symptoms produced by itself. In this group, the invasive lobular cancer was found in seven lesions (64\%). Our finding suggests that LN producing suspicious radiological symptoms can be a different biologic type of this lesion when compared asymptomatic LN diagnosed which is usually found on biopsy as additional microscopic pathology. Symptomatic LN is probably associated with a higher potential of malignant transformation. (Folia Histochemica et Cytobiologica 2011; Vol. 49, No. 3, pp. 417-424)
\end{abstract}

Key words: breast cancer, breast biopsy, lobular carcinoma in situ, atypical lobular hyperplasia, lobular neoplasia

\section{Introduction}

Lobular neoplasia (LN) covers the entire spectrum of lobular disease, ranging from minimal lobular in-

\footnotetext{
Correspondence address: R. Matkowski,

Department of Oncology, Wroclaw Medical University,

$2^{\text {nd }}$ Department of Surgical Oncology,

Lower Silesian Oncology Centre,

Plac Hirszfelda 12, 53-413 Wroclaw, Poland;

tel.: (+ 48 71) 36893 91; fax: (+ 48 71) 36191 11;

e-mail: matkowski.r@dco.com.pl,rem@onet.pl
}

volvement to maximum distention of acini in several lobular units, with or without pagetoid involvement of terminal ducts. Cytologically, the cells of LN have a uniform appearance with distinct cell borders. Pathologically, LN (Figure 1) is characterized by a solid proliferation of loosely cohesive, uniform small cells that fill and distend the acini of a terminal duct lobular unit [1]. In recent decades, there has been a four-fold increase in its incidence, especially in post-menopausal women aged 50-59 years [2]. LN has been typically regarded as a marker of an increased risk of invasive breast cancer (IBC) rather than as a true pre- 
cursor lesion [3]. This concept is also supported by some more recent studies [4]. However, its direct association with invasive lobular carcinoma (ILC) has been postulated by others [5].

The aim of this study was to examine the radiological symptoms and microscopic findings, comparing them to the prevalence, type, and site of the invasive cancer in females with LN found on biopsy.

\section{Material and methods}

Patients. 1,478 women who underwent primary open biopsy or surgical excision after minimal invasive percutaneous biopsy between 2004 and 2008 were studied. In 24 of them (1.6\%), LN was diagnosed. All these lesions were classified as BIRADS 4. Mean (median, range) patient age was 53.8 \pm 3.6 years $(53,37-69)$. Neither breast cancer history nor family history was present. Hormone replacement therapy was being given to five (21\%) women. Mean (median, range) clinical tumor size was $12.8 \pm 0.9 \mathrm{~mm}(13,7-22)$. Palpable mass was found in two $(8 \%)$ females. Status of the estrogen receptor was positive in $21(88 \%)$ patients.

Management. In each case, excision of the lesion was done. In four women, image-guided excisional biopsy with hook-wire localization was done primarily due to the radial scar without mass. In 20 females, surgical excision lesion was performed for histologic assessment of the completely removed lesion because of the presence of LN (with fibroadenoma in nine cases) in specimens from the hand-held vacuum-assisted or core-needle percutaneous biopsy. Postoperative histologic evaluation was done and pathologic findings were compared to the radiological symptoms. A comparison between groups with LN radiologically symptomatic- and asymptomatic-diagnosed as additional histologic finding near the other symptomatic lesion is presented in Table 1.

Open biopsy and wire localization. Two lesions were presented as palpable tumors. For the other non-palpable le- sions, needle localization of the lesion was carried out under local anesthesia. It was performed using an Accura BLN device (Medical Device Technologies Inc, Gainesville, FL, USA; distribution in Europe by PBN Medicals, Stenlose, Denmark) under imaging guidance. After the needle was placed and its position was confirmed, the hook-wire was deployed and the same radiological view was obtained to confirm the wire position.

Minimal invasive biopsy. Percutaneous minimal-invasive biopsy performed under local anesthesia was made as an alternative to open biopsy for adequate pathological examination of the lesion and for optimal treatment planning if further surgical excision was needed. For two palpable tumors, 14-gauge core needle biopsy was performed using an Angiotech device 14 ga $\times 12 \mathrm{~cm}$ (Medical Device Technologies Inc). Eighteen women with non-palpable lesions were referred for image-guided procedures. For five lesions with a diameter equal to or greater than $15 \mathrm{~mm}$, core needle biopsy (as above) was carried out under ultrasonography guidance. For 13 patients with smaller abnormalities, vacuum-assisted biopsy was offered. In five of these cases (two with microcalcifications and three with architectural distortion) stereotactic vacuum-assisted biopsy was done with the patient prone on a designated table with the 11-gauge Mammotome device MST 11 (Mammotest Plus/S, Fisher Imaging, Denver, CO, USA). In the other eight (with sonographic mass lesion) ultrasound-guided biopsy was performed using 11-gauge hand-held probe MHH 11 (Ethicon Endo-Surgery Europe, Norderstedt, Germany). For lesions imaged in both mammography and sonography, biopsy under ultrasound guidance was the preferred option in our institution.

Pathology. All hematoxylin and eosin stained slides of formalin-fixed and paraffin-embedded tissue blocks previously diagnosed in double assessment as lobular carcinoma in situ (LCIS) or atypical lobular hyperplasia (ALH) were

Table 1. Comparison between groups with radiologically asymptomatic and symptomatic LN

\begin{tabular}{|l|c|c|}
\hline Characteristic & Asymptomatic LN group & Symptomatic LN group \\
\hline $\begin{array}{c}\text { Patient age (years) } \\
\text { mean/median/range }\end{array}$ & $54.8 / 53.0 / 38-68$ & $52.0 / 53.0 / 41-65$ \\
\hline $\begin{array}{c}\text { Hormone replacement therapy } \\
\text { positive, n (\%)/negative, n (\%) }\end{array}$ & $3(23 \%) / 10(77 \%)$ & $2(18 \%) / 9(82 \%)$ \\
\hline $\begin{array}{l}\text { Palpable mass } \\
\text { absent, n (\%)/present, n (\%) }\end{array}$ & $12(92 \%) / 1(8 \%)$ & $10(91 \%) / 1(9 \%)$ \\
\hline $\begin{array}{l}\text { Pathologic tumor size [mm] } \\
\text { mean/median/range }\end{array}$ & $13.8 / 13.2 / 9-22^{*}$ & $14.1 / 13.5 / 8-21$ \\
\hline $\begin{array}{c}\text { Estrogen receptor status } \\
\text { positive, n (\%)/negative, } \mathrm{n}(\%)\end{array}$ & $11(85 \%) / 2(15 \%)$ & $10(91 \%) / 1(9 \%)$ \\
\hline
\end{tabular}

*Diameter of symptomatic lesion coexisting with asymptomatic LN 
re-evaluated by a supervising pathologist (A.H.) LN was diagnosed according to the well-defined histological criteria [6]. For a diagnosis of LCIS, all the acini had to be filled, and at least half of them distended by round or oval normochromatic cells that were similar in appearance and placement to each other. ALH lesions were defined as lobular proliferations that exhibited some, but not all, of the features of LCIS, including incomplete involvement of acini within the lobular unit. Focal LN was diagnosed if one lobule or less was involved (Figure 2). When more than one lobule was involved (Figure 3), the case was classified as extensive LN. When there was any doubt about the origin of the lesion (lobular vs. ductal) E-cadherin staining was performed.

\section{Results}

\section{$L N$ without any radiological symptoms}

In 13 women, $\mathrm{LN}$ did not produce any radiological symptoms and was an incidental histologic finding existing near the other lesion: fibroadenoma in nine cases (Figures 4 and 5) and radial scar in four (Figure 6). All these cases were classified as focal LN. In none of these lesions was an ILC noticed. In one of these patients (8\%), ductal carcinoma in situ (DCIS) was found in the other segment of the ipsilateral breast and in another one (8\%), infiltrating ductal cancer (IDC) developed in the contralateral breast.

\section{LN diagnosed due to itself with imaging techniques}

In 11 females, LN was diagnosed with imaging techniques as BIRADS 4 lesion due to radiological symptoms produced by itself (Figures 7-9). There were six lesions with mass, three with architectural distortion, and two with microcalcifications. All these lesions were classified as extensive LN. In this group, ILC was found in seven lesions (64\%). Six of them were diagnosed as mass lesions, one as architectural distortion. No other malignancy was observed in the ipsior contralateral breast in these women. None of the lesions associated with microcalcifications was histologically upgraded after surgical excision. Findings are presented in Table 2.

\section{Discussion}

The reported relative risk, compared to women in the general population, for developing subsequent IBC after an incidental finding of LN in a biopsy, ranges in long-term follow-up studies from 3.0-4.2-fold $[2,7]$ to $5.9-12.0$-fold $[8,9]$. Approximately $50 \%$ of them are believed to occur more than 15 years after $\mathrm{LN}$

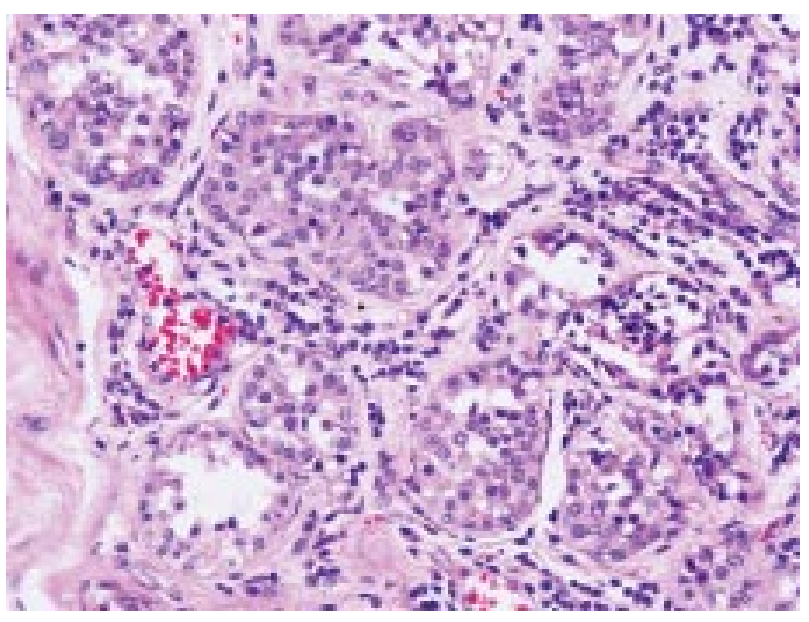

Figure 1. Lobular neoplasia - the solid proliferation of loosely cohesive, uniform small cells fill and distend the acini of a terminal duct lobular unit. (H\&E, magnification $\times 200$ )

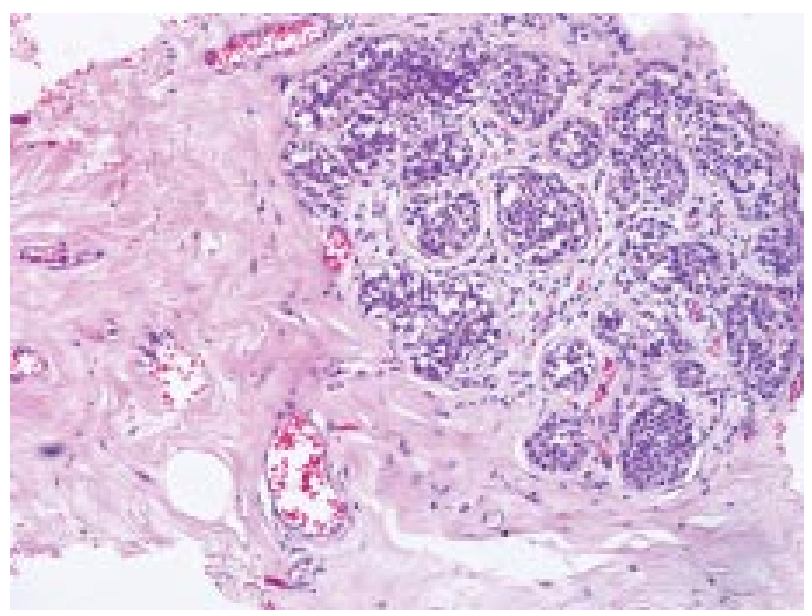

Figure 2. Focal lobular neoplasia with one lobule in one core involved. $(\mathrm{H} \& \mathrm{E}$, magnification $\times 100)$

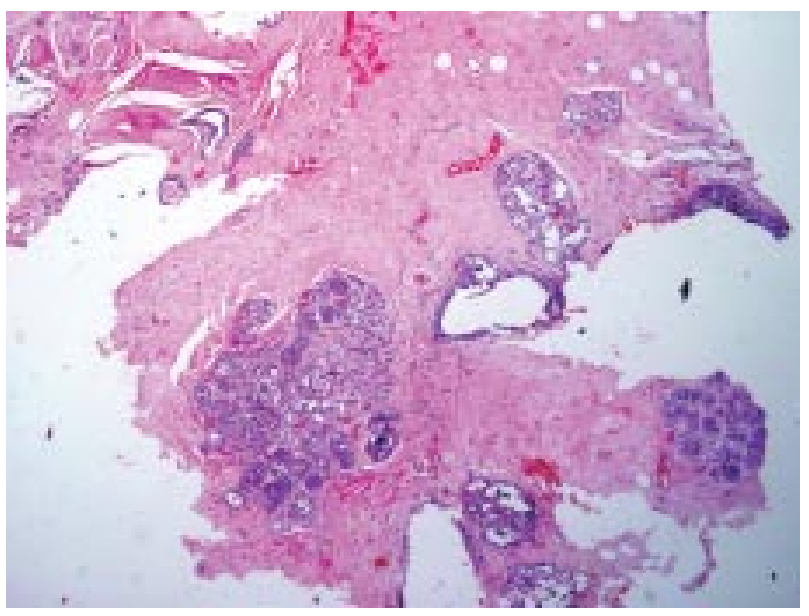

Figure 3. Diffuse LN with multiple lobules involved in one core. $(\mathrm{H} \& \mathrm{E}$, magnification $\times 20$ ) 


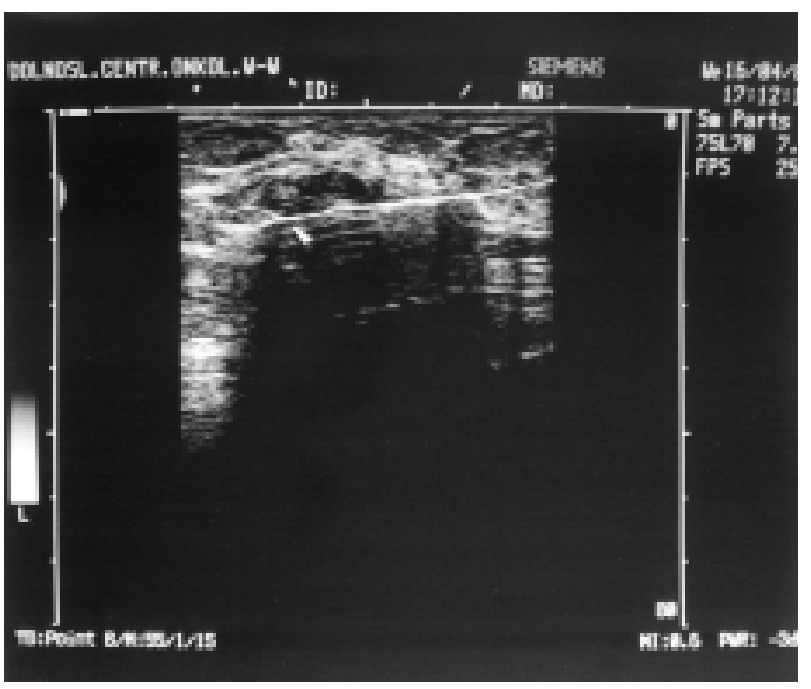

Figure 4. Lobular neoplasia as incidental histologic finding associated with fibroadenoma. Photo with hand-held 11-Gauge vacuum-assisted biopsy probe. The same patient as on Figure 5

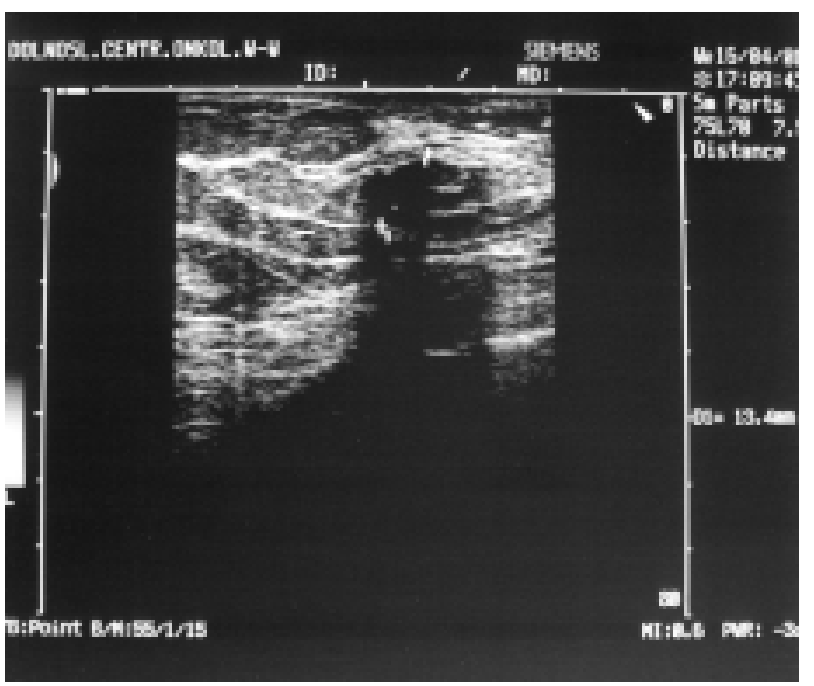

Figure 5. Lobular neoplasia as incidental histologic finding associated with fibroadenoma. The same patient as on Figure 4

diagnosis, while $38 \%$ occur more than 20 years later. The risk over 15 to 20 years is $10 \%$ to $20 \%$ (5). It is spread over long periods, being about $0.5 \%$ to $1 \%$ per year, which seems to be a consequence of the relatively low proliferative rate of these lesions [9].

LN has been typically regarded as a non-surgical disease and viewed as a marker of an increased risk of IBC, rather than as a true precursor lesion [3]. Some more recent papers have shown that women with $\mathrm{LN}$ found on breast biopsy without concurrent malignancy are at increased risk for the subsequent development of IBC, either ipsi- or contralateral,

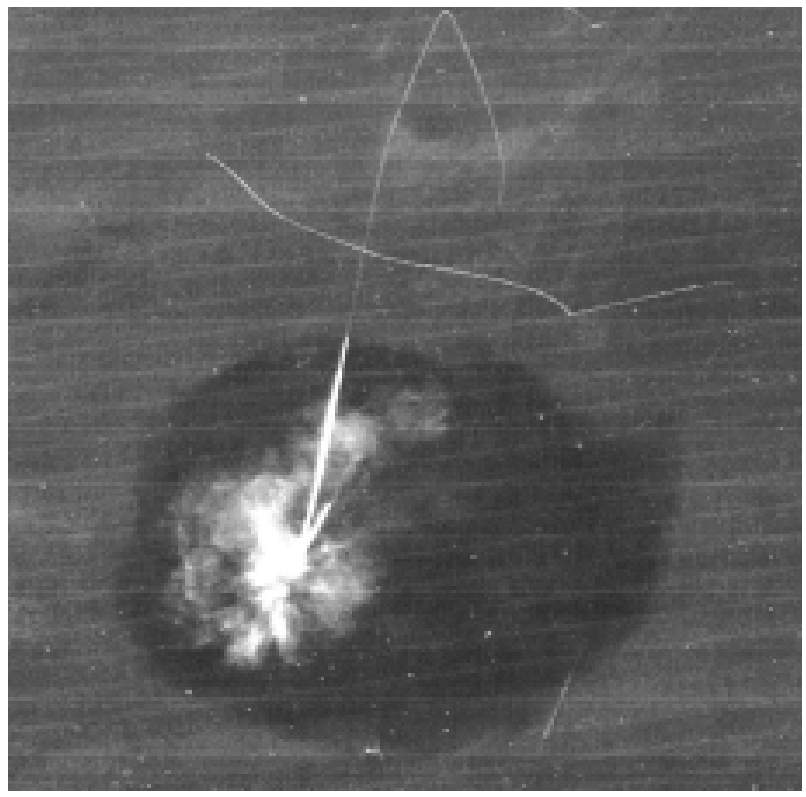

Figure 6. Lobular neoplasia as incidental histologic finding next to radial scar lesion. Photo of excised specimen with hook-wire

ductal or lobular [10-14]. However, the results of other studies with long-term follow-ups showed an approximately two-fold increased incidence of IBC in the ipsilateral breast compared to the contralateral one in women with LN diagnosed in minimal-invasive biopsy $[15,16]$. Nearly $50 \%$ of the subsequent cancers are categorized as tumors with good prognosis, i.e.: ILC, tubular, tubulo-lobular, ring cell, medullary [16]. Our findings confirm the concept that LN is an indicator of higher risk for more significant disease (DCIS or IBC), but only in regard to asymptomatic focal $\mathrm{LN}$ coexisting with another radiologically symptomatic lesion.

On the other hand, there is growing evidence that $\mathrm{LN}$ is a direct precursor of ILC. Recent studies showed that three out of four cases of IBC occur in the ipsilateral breast and the subsequent cancer is usually an infiltrating lobular carcinoma (ILC) or has a prominent lobular component [17-20]. The percentage of ILC, regarding the type of IBC diagnosed after $\mathrm{LN}$, has also been reported over $50 \%$ by others $[21,22]$ while only $5-10 \%$ of IBCs without a history of LN are of lobular histology [22].

Findings from the SEER study of 45,871 patients showed that women with LCIS are more likely to develop ipsilateral IBC ( $0.73 \%$ vs. $0.54 \%)$, are 5.3 -fold more likely to develop ILC, and are 0.8 -fold less likely to develop invasive ductal cancer compared to women with ductal carcinoma in situ [23]. LN is present in up to $12 \%$ of early IBC [24] and is 25 -fold more likely to be associated with ILC than with ductal one [25]. 

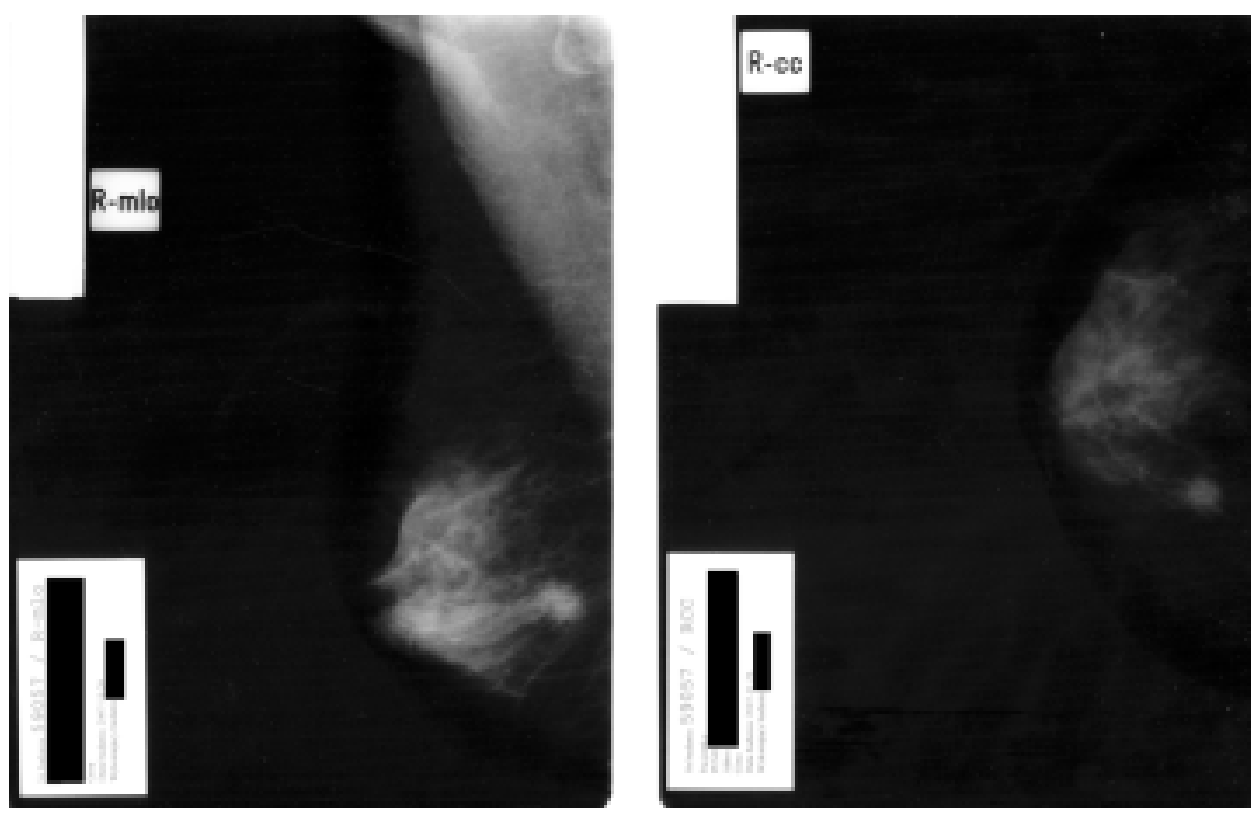

Figure 7. Radiologically symptomatic LN presented as mass lesion classified as BIRADS 4

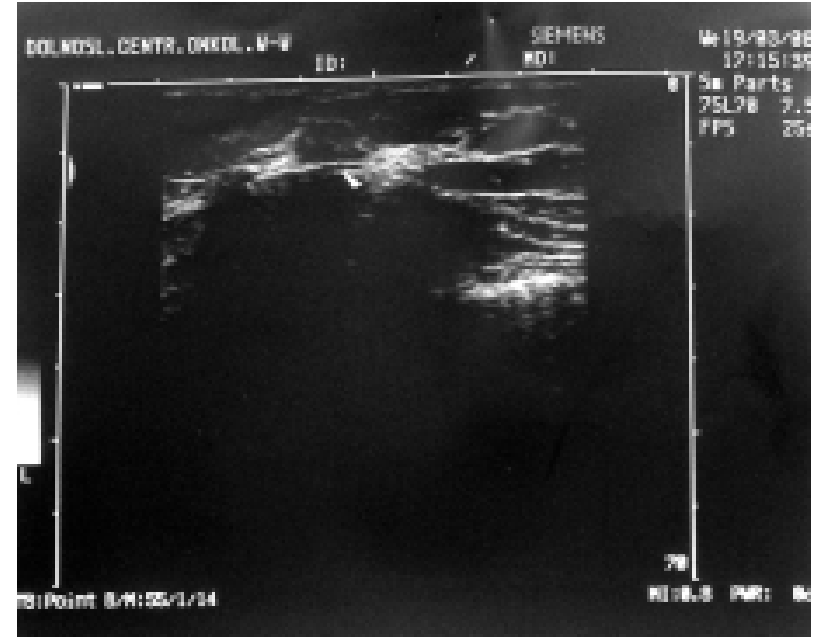

Figure 8. Radiologically symptomatic LN presented in sonography as mass lesion classified as BIRADS 4 . Photo with hand-held 11-Gauge vacuum-assisted biopsy probe. The same patient as on Figure 9

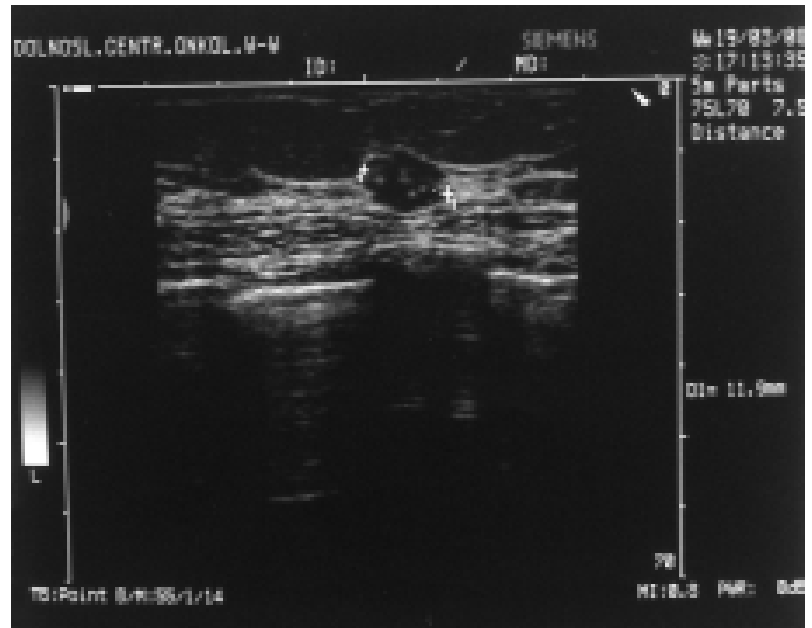

Figure 9. Radiologically symptomatic LN presented in sonography as mass lesion classified as BIRADS 4.

Photo without probe. The same patient as on Figure 8

Table 2. Imaging and pathologic findings

\begin{tabular}{|l|c|c|c|}
\hline Group & Lesion histology & Radiological presentation & $\begin{array}{c}\text { Other breast malignancy, } \\
\text { ipsi- or contralateral }\end{array}$ \\
\hline Asymptomatic & $\begin{array}{c}\text { LN + fibroadenoma, } \mathrm{n}=9 \\
\mathrm{LN}+\text { radial scar, } \mathrm{n}=4\end{array}$ & $\begin{array}{c}\text { Mass, } \mathrm{n}=9 \\
\text { Architectural distortion, } \mathrm{n}=4\end{array}$ & $\begin{array}{c}\text { DCIS in ipsilateral breast } \\
\text { IDC in contralateral breast }\end{array}$ \\
\hline Symptomatic & $\begin{array}{c}\mathrm{LN} \text { only, } \mathrm{n}=4 \\
\mathrm{LN}+\mathrm{ILC}, \mathrm{n}=7\end{array}$ & $\begin{array}{c}\text { Mass, } \mathrm{n}=6 \\
\text { Architectural distortion, } \mathrm{n}=3 \\
\text { Microcalcifications, } \mathrm{n}=2\end{array}$ & None \\
\hline
\end{tabular}

DCIS — ductal carcinoma in situ; IDC — invasive ductal cancer; ILC — invasive lobular cancer 
The ten-year cumulative incidence rate of ipsilateral breast cancer recurrence after breast-conserving therapy for IBC can be five-fold increased when concurrent $\mathrm{LN}$ is present. Most recurrent tumors are invasive and are located in the vicinity of the primary IBC [25]. The risk of concurrent ILC within the radiologically symptomatic LN was as high as $64 \%$ in our study, and the lack of the other ipsi- and contralateral IBC support the precursor-product relationship between these lesions. Genetic studies have attempted to prove a genetic correlation between LCIS and ILC when they appear synchronously and to clarify whether LN serves as a precursor for the development of invasive lobular cancer or is a marker for advanced genetic changes in breast tissue.

However, the answer to the question of whether $\mathrm{LN}$ is a premalignant lesion or a heterogenous disease is still not definitively determined [26].

There are no accepted guidelines for the management of LN diagnosed on core-needle or vacuum-assisted breast biopsy [27]. There was no increased risk of IBC in the site of lesion in subsequent surgical excision of LN diagnosed in biopsy in some studies [28-30]. On the contrary, in other series, the rate of LN upgraded to IBC or DCIS ranged from $17 \%$ to $42 \%$ [31-36]. Esserman et al. noticed ILC after excision only in two of 26 patients with $\mathrm{LN}$ diagnosed on core [37]. In these cases, ILC was associated with diffuse $\mathrm{LN}$, and no ILC was observed when LN was diagnosed as focal.

These findings are partly similar to ours, indicating that excision may not be necessary when only focal LN is found on core biopsy. Moreover, it suggests that symptomatic diffuse $\mathrm{LN}$ can be a direct precancerous lesion for ILC. Lechner et al. in a multi-institutional study of 32,424 lesions in which minimal-invasive breast biopsy was performed found $34 \%$ of $\mathrm{LN}$ lesions diagnosed at percutaneous biopsy to be malignant at excision [38]. The increased risk of underestimation of LN diagnosed in biopsy is significantly associated with higher BIRADS category, mass lesions (vs. microcalcifications), and use of a core biopsy (vs. vacuum-assisted) [39]. In the study by Bauer et al. IBC was noticed on surgical biopsy only in one patient with $\mathrm{LN}$ associated with benign fibrocystic disease diagnosed on core [40]. However, this rate increased to $27 \%$ when radial scar, atypical hyperplasia, intraductal papilloma or phyllodes tumor were found with LN on percutaneous biopsy.

Due to these discrepancies, many authors recommend an individual approach, claiming that LN should be excised when: ductal involvement is found [41]; $\mathrm{LN}$ is associated with atypical ductal hyperplasia [42]; residual microcalcifications are seen [17]; at least ten lobules are involved [34]; another high-risk or bor- der-line lesion is present [43, 44]; it is not possible to exclude DCIS despite E-cadherin immunochemistry [44]; and LN is pleomorphic or with necrosis [44, 45]. Final management based on a consideration of the outcomes at one's own institution is recommended by some as the most reasonable option [17].

Middleton et al., describing the MD Anderson experience with LN on core-needle biopsy, found IBC in $35 \%$ of symptomatic lesions [45]. Similarly to us, most of them (83\%) were seen as mass-forming lesions. The need for re-biopsy of all atypical hyperplasia lesions is also emphasized by others [46]. In our study, only LN diagnosed as BIRADS 4 lesions were analyzed. Based on the recent reports, the positive predictive value for malignancy is $44-61 \%$ for $\mathrm{LN}$ seen as BIRADS 3 tumors and $85-90 \%$ for $\mathrm{LN}$ viewed as BIRADS 4 lesion [47, 48]. It is also increased for LCIS and tumors larger than $2 \mathrm{~cm}$ when compared to ALH and smaller lesions: $57.1 \%$ vs. $7.1 \%$, and $100 \%$ vs. $31.2 \%$, respectively [49]. Interestingly, there was significantly increased risk of IBC in the site of mass-forming LN reported in the study from Nottingham University Hospital, but the authors claimed that it was the result of biopsy missing the radiologically symptomatic lesion next to incidental LN [44]. When $\mathrm{LN}$ is not a direct precancerous lesion, the possible reason of the increased risk of IBC is the misdiagnosis in pathological assessment. Histologic differentiation of LN and DCIS is usually not difficult, but areas of overlap exist. In follow-up surgery, up to $20 \%$ of all $\mathrm{LN}$ and up to $50 \%$ of mass-forming $\mathrm{LN}$ can be upgraded to DCIS [50]. In addition, the fragmentation of lesion after minimal-invasive biopsy increases the challenge to diagnose these lesions correctly [50].

Some authors believe the available data remains inadequate to make a definitive determination of the best management policy for $\mathrm{LN}$ diagnosed on percutaneous biopsy [51]. Others claim that $\mathrm{LN}$ should be always regarded as a high risk lesion and that wide excision after core biopsy is needed [52].

Because of a high rate of ILC within radiologically symptomatic $\mathrm{LN}$ in our series, subsequent removal with clear margins is the preferred option in our institution. Our findings support the concept that ILC can develop directly from the clonal expansion of the cells present in LN lesions. Further studies are needed to clarify this possible precursor-product relationship. More research is required to understand the long-term pathogenic implications of LN diagnosis in minimal-invasive breast biopsy.

\section{Acknowledgements}

This study was supported by a research fellowship within the 'Development program of Wroclaw Medi- 
cal University' funded from European Social Fund, Human Capital, National Cohesion Strategy (contract no. UDA-POKL.04.01.01-00-010/08-00).

\section{References}

1. Lishman SC, Lakhani SR. Atypical lobular hyperplasia and lobular carcinoma in situ: surgical and molecular pathology. Histopathology. 1999;35:195-200.

2. Li CI, Anderson BO, Daling JR, Moe RE. Changing incidence of lobular carcinoma in situ of the breast. Breast Cancer Res Treat. 2002;75:259-268.

3. Frygberg ER, Santiago F, Betsill WL Jr, O'Brien PH. Lobular carcinoma in situ of the breast. Surg Gynecol Obstet. 1987;164:285-301.

4. Zagouri F, Sergentanis TN, Zografos GC. Precursors and preinvasive lesions of the breast: the role of molecular prognostic markers in the diagnostic and therapeutic dilemma. World J Surg Oncol. 2007;5:57.

5. Arpino G, Laucirica R, Elledge RM. Premalignant and in situ breast disease: biology and clinical implications. Ann Intern Med. 2005;143:446-457.

6. Page DL, Anderson TJ, Rogers LN. Lobular carcinoma in situ. In: Page DL, Anderson TJ (ed.). Diagnostic histopathology of the breast. $3^{\text {rd }}$ edition, Churchill Livingston, New York; 1987:174-182.

7. Warnberg F, Yuen J, Holmberg L. Risk of subsequent invasive breast cancer after breast carcinoma in situ. Lancet. 2000;355:724-725.

8. Page DL, Kidd TE Jr, Dupont WD, Simpson JF, Rogers LW. Lobular neoplasia of the breast: higher risk for subsequent invasive cancer predicted by more extensive disease. Hum Pathol. 1991;22:1232-1239.

9. Rosen PP. Lobular carcinoma in situ. In: Rosen PP (ed.). Rosen's Breast Pathology. $2^{\text {nd }}$ edition, Lippincott, Williams \& Wilkins, Philadelphia; 2001:581-626.

10. Marshall LM, Hunter DJ, Connolly JL et al. Risk of breast cancer associated with atypical hyperplasia of lobular and ductal types. Cancer Epidemiol Biomarkers Prev. 1997;6:297-301.

11. Wood WW. Management of lobular carcinoma in situ and ductal carcinoma in situ of the breast. Semin Oncol. 1996; 23:446-452.

12. Frygberg ER. Lobular carcinoma in situ of the breast. Breast J. 1999;5:296-302.

13. Shaaban AM, Sloane JP, West CR, Moore FR, Jarvis C, Williams EM. Histopathologic types of benign breast lesions and the risk of breast cancer: case-control study. Am J Surg Pathol. 2002;26:421-430.

14. Claus EB, Stowe M, Carter D, Holford T. The risk of a contralateral breast cancer among women diagnosed with ductal and lobular carcinoma in situ: data from the Connecticut Tumor Registry. Breast. 2003;12:451-456.

15. Collins LC, Baer HJ, Tamimi RM, Connolly JL, Colditz GA, Schnitt SJ. Magnitude and laterality of breast cancer risk according to histologic type of atypical hyperplasia. Cancer. 2007;109:180-187.

16. McLaren B, Schuyler PA, Sanders ME et al. Excellent survival, cancer type, and Nottingham grade after atypical lobular hyperplasia on initial breast biopsy. Cancer. 2006; 107:1227-1233 .

17. Berg WA, Mrose HE, Ioffe OB. Atypical lobular hyperplasia or lobular carcinoma in situ at core-needle breast biopsy. Radiology. 2001;218:503-509.

18. Page DL, Schuyler PA, Dupont WD, Jensen RA, Plummer WD Jr, Simpson JF. Atypical lobular hyperplasia as a unilat- eral predictor of breast cancer risk: a retrospective cohort study. Lancet. 2003;361:125-129.

19. Burak WE Jr, Owens KE, Tighe MB et al. Vacuum-assisted stereotactic breast biopsy: histologic underestimation of malignant lesions. Arch Surg. 2000;135:700-703.

20. Fisher ER, Land SR, Fisher B, Mamounas E, Gilarski L, Wolmark N. Pathologic findings from the National Surgical Adjuvant Breast and Bowel Project: twelve-year observations concerning lobular carcinoma in situ. Cancer. 2004;100: 238-244.

21. Bodian CA, Perzin KH, Lattes R. Lobular neoplasia: longterm risk of breast cancer and relation to other factors. Cancer. 1996;78:1024-1034.

22. Schnitt SJ, Guidi AJ. Pathology of invasive breast cancer. In: Harris JR, Lippman ME, Morrow M, Osborne CK (ed.). Diseases of the Breast. $3^{\text {rd }}$ edition, Lippincott Williams \& Wilkins, Philadelphia; 2000:2562-2572.

23. Li CI, Malone KE, Saltzman BS, Daling JR. Risk of invasive breast carcinoma among women diagnosed with ductal carcinoma in situ and lobular carcinoma in situ, 1988-2001. Cancer. 2006;106:2104-2112.

24. Abner AL, Connolly JL, Recht A et al. The relationship between the presence and extent of lobular carcinoma in situ and the risk of local recurrence for patients with infiltrating carcinoma of the breast treated with conservative surgery and radiation therapy. Cancer. 2000;88:1072-1077.

25. Sasson AR, Fowble B, Hanlon AL et al. Lobular carcinoma in situ increases the risk of local recurrence in selected patients with stage I and II breast carcinoma treated with conservative surgery and radiation. Cancer. 2001;91:1862-1869.

26. Barsky SH, Bose S. Should LCIS be regarded as a heterogeneous disease? Breast J. 1999;5:407-412.

27. Hanby AM, Hughes TA. In situ and invasive lobular neoplasia of the breast. Histopathology. 2008;52:58-66.

28. Renshaw AA, Cartagena N, Derhagopian RP, Gould EW. Lobular neoplasia in breast core needle biopsy specimens is not associated with an increased risk of ductal carcinoma in situ or invasive carcinoma. Am J Clin Pathol. 2002;117:797-799.

29. Sohn VY, Arthurs ZM, Kim FS, Brown TA. Lobular neoplasia: is surgical excision warranted? Am Surg. 2008;74: $172-177$.

30. Nagi CS, O’Donnell JE, Tismenetsky M, Bleiweiss IJ, Jaffer SM. Lobular neoplasia on core needle biopsy does not require excision. Cancer. 2008;112:2152-2158.

31. Elsheikh TM, Silverman JF. Follow-up surgical excision is indicated when breast core needle biopsies show atypical lobular hyperplasia or lobular carcinoma in situ: a correlative study of 33 patients with review of the literature. Am J Surg Pathol. 2005;29:534-543.

32. Foster MC, Helvie MA, Gregory NE, Rebner M, Nees AV, Paramagul C. Lobular carcinoma in situ or atypical lobular hyperplasia at core-needle biopsy: is excisional biopsy necessary? Radiology. 2004;231:813-819.

33. Dmytrasz K, Tartter PI, Mizrachy $\mathrm{H}$ et al. The significance of lobular hyperplasia at percutaneous breast biopsy. Breast $J$. 2003;9:10-12.

34. Ottesen GL, Graversen HP, Blichert-Toft M, Zedeler K, Andersen JA. Lobular carcinoma in situ of the female breast: short-term results of a prospective nationwide study — the Danish Breast Cancer Cooperative Group. Am J Surg Pathol. 1993;17:14-21.

35. O'Driscoll D, Britton P, Bobrow L, Wishart GC, Sinnatamby R, Warren R. Lobular carcinoma in situ on core biopsy - what is the clinical significance? Clin Radiol. 2001; $56: 216-220$. 
36. Mahoney MC, Robinson-Smith TM, Shaughnessy EA. Lobular neoplasia at 11-gauge vacuum-assisted stereotactic biopsy: correlation with surgical excisional biopsy and mammographic follow-up. AJR Am J Roentgenol. 2006;187:949-954.

37. Esserman LE, Lamea L, Tanev S, Poppiti R. Should the extent of lobular neoplasia on core biopsy influence the decision for excision? Breast J. 2007;13:55-61.

38. Lechner MC, Jackman RJ, Brem RF, Evans WP III, Parker SH, Smid AA. Lobular carcinoma in situ and atypical lobular hyperplasia at percutaneous biopsy with surgical correlation: a multi-institutional study. Radiology. 1999;213(P):106.

39. Brem RF, Lechner MC, Jackman RJ et al. Lobular neoplasia at percutaneous breast biopsy: variables associated with carcinoma at surgical excision. AJR Am J Roentgenol. 2008; 190: 637-641.

40. Bauer VP, Ditkoff BA, Schnabel F, Brenin D, El-Taner M, Smith S. The management of lobular neoplasia identified on percutaneous core breast biopsy. Breast J. 2003;9:4-9.

41. Page DL, Steel CM, Dixon JM. ABC of breast diseases: carcinoma in situ and patients at high risk of breast cancer. $\mathrm{Br}$ Med J. 1995;310:39-42.

42. Arpino G, Allred DC, Mohsin SK, Weiss HL, Conrow D, Elledge RM. Lobular neoplasia on core-needle biopsy - clinical significance. Cancer. 2004;101:242-250.

43. Liberman L, Sama M, Susnik B et al. Lobular carcinoma in situ at percutaneous breast biopsy: surgical biopsy findings. AJR Am J Roentgenol. 1999;173:291-299.

44. Menon S, Porter GJR, Evans AJ et al. The significance of lobular neoplasia on needle core biopsy of the breast. Virchows Arch. 2008;452:473-479.
45. Middleton LP, Grant S, Stephens T, Stelling CB, Sneige N, Sahin AA. Lobular carcinoma in situ diagnosed by core needle biopsy: when should it be excised? Mod Pathol. 2003; 16:120-129.

46. Dershaw DD, Morris EA, Liberman L, Abramson AF. Non-diagnostic stereotaxic core breast biopsy: results of rebiopsy. Radiology. 1996;198:323-325.

47. Houssami N, Ciatto S, Bilous M, Vezzosi V, Bianchi S. Borderline breast core needle histology: predictive values for malignancy in lesions of uncertain malignant potential (B3). Br J Cancer. 2007;96:1253-1257.

48. Dillon MF, McDermott EW, Hill AD, O'Doherty A, McDermott EW, O'Higgins N. Predictive value of breast lesions of "uncertain malignant potential" and "suspicious of malignancy" determined by needle core biopsy. Ann Surg Oncol. 2007; 14:704-711.

49. Londero V, Zuiani C, Linda A, Vianello E, Furlan A, Bazzocchi M. Lobular neoplasia: core needle breast biopsy underestimation of malignancy in relation to radiologic and pathologic features. Breast. 2008;17:623-630.

50. Philpotts LE, Shaheen NA, Jain KS, Carter D, Lee CH. Uncommon high-risk lesions of the breast diagnosed at stereotactic core-needle biopsy: clinical importance. Radiology. 2002;216:831-837.

51. Dershaw D. Does LCIS or ALH without other high-risk lesions diagnosed on core biopsy require surgical excision? Breast J. 2003;9:1-3.

52. Elsheikh TM, Silverman JF. Wider excision following core biopsies of lobular neoplasia. Breast J. 2007;13:631-632.

Submitted: 30 August, 2010 Accepted after reviews: 17 March 2011 